\title{
El poder: de la complejidad a la incertidumbre
}

\author{
Power: from complexity to uncertainty
}

\author{
Mario Andrés Alvarado Lozano \\ Magister en Ciencia Política por la Universidad Autónoma de Bucaramanga; Abogado, psicólogo y profesional en \\ Estudios Literarios; docente investigador de la Universidad de Santander UDES, Sede Valledupar, Colombia
} Correo electrónico: alvaradoma001@hotmail.com

\section{Resumen}

En el presente trabajo, haciendo uso de una investigación de tipo exploratoria y descriptiva, se caracteriza a los concejales de Barrancabermeja elegidos para el período 2012-2015. Se tuvieron como objetivos, establecer cuál es la trayectoria y los principales aspectos que identifican a los concejales elegidos. Dentro de las conclusiones se destaca que los concejales se dedican tiempo parcial a su función, cuentan con la formación académica necesaria para pensar que tienen las dotes requeridas para hacer una aceptable gestión, y algunos tienen experiencia, tanto por fuera como en el interior de partidos políticos. Finalmente, parece claro que el modelo que domina el escenario, es el modelo decisionista, ni el modelo tecnocrático ni el pragmatista parecen tener cabida desde la caracterización realizada.

Palabras clave: Dedicación, talento, experiencia, concejales, caracterización, modelo pragmatista.

\begin{abstract}
In the present work, using exploratory research and descriptive, is characterized Barrancabermeja councilors elected for the period 2012-2015. They were taken as targets, establish what is the path and the main aspects that identify elected councilors. Among the conclusions, highlighting that councilors are engaged in part-time function, have the academic background necessary to think they have the skills required to make an acceptable management, and some have experience both outside and inside games politicians. Finally, it seems clear that the model that dominates the stage, is the decisionist model, nor the technocratic model or the pragmatist seem to fit from this characterization.
\end{abstract}

Keywords: Dedication, talent, experience, aldermen, characterization, model pragmatist.

\section{Résumé}

Dans le présent travail, la recherche en utilisant exploratoire et descriptive, se caractérise conseillers Barrancabermeja élus pour la période 2012-2015. Ils ont été pris comme cibles, établir ce que la trajectoire et les principaux aspects qui identifient les conseillers élus. Parmi les résultats, souligne que les conseillers sont engagés dans le temps partiel la fonction, ils ont la formation universitaire nécessaire à penser qu'ils ont les compétences requises pour faire une gestion acceptable, et certains ont l'expérience des deux jeux à l'extérieur et à l'intérieur politiciens. Enfin, il semble clair que le modèle qui domine la scène, est le modèle de décisionniste, ni le modèle technocratique, ni le pragmatiste semblent être logés à partir de la caractérisation faite.

Mots-clés: Dédicace, talent, expérience, Echevins, caractérisation, Modèle pragmatiste. 

EL PODER: DE LA COMPLEJIDAD A LA INCERTIDUMBRE

Mario Andrés Alvarado Lozano

\section{INTRODUCCIÓN}

La profesionalización de la política es un tema de profunda importancia para el sistema político, el mundo de la política se ha convertido en un escenario que es común para los sueños de muchos ciudadanos. Con la consolidación del modelo de democracia representativa, comienza a cobrar vigencia lo planteado por Max Weber y que puede resumirse en una frase, "vivir para la política y vivir de la política" (Weber, 1967). Con la profesionalización de la política, entra en juego el actor que llamamos político, en los recientes años se le ha dado un papel protagónico a las instituciones, bajo el supuesto que estas son las que explican la realidad política, pero los políticos son quienes con sus cualidades o debilidades convierten en realidad los ideales de cualquier sistema político, sistema económico o sistema social. El retorno hacia el actor, es decir, el regreso hacia el político, permite conocer más a profundidad como concibe este al mundo en el que se mueve, al mundo que lo rodea.

Caracterizar a los concejales de Barrancabermeja elegidos para el período 20122015 a través de una encuesta autodiligenciada es interesante, además de analizar cuál es la trayectoria de cada uno de los participantes y los principales aspectos que identifican a los concejales elegidos para el período 2012-2015 en la ciudad de Barrancabermeja. Predecir los fenómenos sociales es muy complejo, por supuesto todo se encuentra en el marco de un principio de incertidumbre fundamental, la lógica de la política no escapa a este principio y es por esto, que analizar el tema de la profesionalización de la política, es un tema álgido para cualquier democracia.

\section{ANTECEDENTES Y PROCESO METODOLÓGICO DEL PROYECTO}

La presente investigación es de tipo exploratorio y descriptivo. Se aplicó una encuesta autodiligenciada a la población seleccionada para el desarrollo del proyecto, concejales municipales de Barrancabermeja. El período para seleccionar los concejales fue el de 2012-2015 y se tuvo en cuenta al número total (17) que integran la corporación. Igualmente, se aplicó entre el mes de mayo y septiembre de 2014 el instrumento a los diecisiete (17) concejales de Barrancabermeja. Se aplicó una 
prueba piloto a cinco (05) personas de iguales o similares características en el mes de mayo de 2014, con la finalidad de probar la encuesta en cuanto a claridad, estructuras de las preguntas y pertinencia de estas.

La encuesta autodiligenciada constaba de tres (03) partes, con treinta y siete (37) preguntas. La primera parte referida a información socio-económica con cinco (05) preguntas de selección múltiple, la segunda parte correspondió a información familiar con cuatro (04) preguntas, dos preguntas de respuesta cerrada y dos de selección múltiple, la tercera parte correspondió a información específica con veintiocho (28) preguntas, seis preguntas de respuesta cerrada y (22) de selección múltiple.

Las categorías temáticas que se establecieron para su posterior análisis fueron las siguientes:

a) Dedicación: Categoría que establece si el político ejerce su cargo público tiempo completo o tiempo parcial.

b) Talento: Categoría que establece si en el ejercicio del político se pueden identificar dotes innatas, mixtas o adquiridas.

c) Experiencia: Categoría que establece qué tipo de actividad ha ejercido el político antes de su llegada en propiedad a la escena política, si la actividad ha sido principalmente por fuera de la política o en su interior.

d) Talento sumado a la experiencia: Categoría que establece en qué medida el político ha sido capaz de sumar las dos anteriores categorías, para convertirse en un político con más oficio y más profesional.

Los resultados de las elecciones para el Concejo de Barrancabermeja período 2012-2015 fueron los siguientes:

Tabla 1. Resultados elecciones para Concejo de Barrancabermeja 2012-2015

\begin{tabular}{lccc}
\hline \multicolumn{1}{c}{ Partido político } & Curules & Porcentaje & Votos \\
\hline Partido Liberal Colombiano & 3 & $15,50 \%$ & 14.018 \\
Partido Verde & 2 & $12,26 \%$ & 11.087 \\
$\begin{array}{l}\text { Mov. Autoridades Indígenas } \\
\text { de Colombia }\end{array}$ & 2 & $11,25 \%$ & 10.174 \\
$\begin{array}{l}\text { Partido Cambio Radical } \\
\text { Partido Alianza Social }\end{array}$ & 2 & $10,31 \%$ & 9324 \\
$\begin{array}{l}\text { Indígena } \\
\begin{array}{l}\text { Partido Social de Unidad } \\
\text { Nacional }\end{array}\end{array}$ & 2 & $9,63 \%$ & 8712 \\
$\begin{array}{l}\text { Compromiso Cívico } \\
\begin{array}{l}\text { Independiente } \\
\text { Polo Democrático }\end{array}\end{array}$ & 2 & $9,04 \%$ & 8175 \\
$\begin{array}{l}\text { Alternativo } \\
\text { Partido de Integración }\end{array}$ & 1 & $8,46 \%$ & 7655 \\
Nacional & 1 & $6,96 \%$ & 6297 \\
\hline
\end{tabular}


Los concejales encuestados fueron los siguientes:

Tabla 2. Concejales seleccionados para aplicar la encuesta autodiligenciada

\begin{tabular}{lll}
\hline \multicolumn{1}{c}{ Partido político } & \multicolumn{1}{c}{ Nombre } & Votos \\
\hline Partido Liberal Colombiano & Carlos Andés González Mebarak & 2792 \\
Partido Liberal Colombiano & Alfonso Baeza Acuña & 1600 \\
Partido Liberal Colombiano & Rogelio Adolfo Scarpetta Díaz & 1234 \\
Partido Verde & Holman José Jiménez Martínez & 2168 \\
Partido Verde & Luis Eduardo Velásquez & 1584 \\
Mov. Autoridades Indígenas de Colombia & Luis Manuel Toro & 1227 \\
Mov. Autoridades Indígenas de Colombia & Malgareth Sánchez Mármol & 1136 \\
Partido Cambio Radical & Pedro Luis Gómez Martínez & 1656 \\
Partido Cambio Radical & René Antonio Tordecilla Reina & 1074 \\
Partido Alianza Social Independiente & Darinel Villamizar Ruiz & 2008 \\
Partido Alianza Social Independiente & Oscar Iván Vásquez Afanador & 1461 \\
Partido Social de Unidad Nacional & Kelly Zulima Ortiz Calao & 1372 \\
Partido Social de Unidad Nacional & Jaime Enrique Quintanilla Archila & 1331 \\
Compromiso Ciudadano Integral & Roberto Quiroga Garcés & 1441 \\
Compromiso Ciudadano Integral & Miriam Guerrero Tovar & 808 \\
Polo Democrático Alternativo & Wilmar Vergara Robles & 653 \\
Partido de Integración Nacional & Oscar José Llorente Guerrero & 891 \\
\hline
\end{tabular}

Fuente: Registraduría Nacional del Estado Civil. www.registraduria.gov.co

\section{Dedicación}

Tabla 3. Dedicación a la política por parte de los concejales

\begin{tabular}{ccccc}
\hline Dedicación a la política & Frecuencia & Porcentaje \% & Válido \% & Acumulado \\
\hline Total & 2 & 11,8 & 11,8 & 11,8 \\
Parcial & 15 & 88,2 & 88,2 & 100,0 \\
\hline Total & 17 & 100,0 & 100,0 & \\
\hline
\end{tabular}

Fuente: El autor.

Se puede inferir, que los concejales desarrollan actualmente diferentes tipos de actividades, este aspecto es clave en el análisis y en la construcción de conclusiones, ya que tiene que ver este aspecto con algo puntual, que es la dedicación de tiempo completo o parcial de los líderes políticos. El perfil de este grupo de concejales es el de un grupo de personas que tienen o manejan distintas actividades simultáneamente, 
la formación como líderes de los concejales, los ha llevado por distintos campos y cargos, como el de ser profesores, el de hacer trabajo comunitario, el de ejercer su profesión particular de forma dependiente o independiente o el de ser asesores principalmente en la esfera de lo privado. En los concejales municipales no se presenta una dedicación exclusiva en cuanto a su función.

\section{Talento}

Tabla 4. Nivel de escolaridad de concejales

\begin{tabular}{lcccc}
\hline $\begin{array}{c}\text { Nivel de } \\
\text { escolaridad }\end{array}$ & Frecuencia & Porcentaje & \%Válido & \%Acumulado \\
\hline Ninguna & 3 & 17,6 & 17,6 & 17,6 \\
Tecnológica & 1 & 5,9 & 5,9 & 23,5 \\
Universitaria & 7 & 41,1 & 41,1 & 64,6 \\
Posgrado & 6 & 35,4 & 35,4 & 100,0 \\
\hline \multicolumn{1}{c}{ Total } & 17 & 100,0 & 100,0 & \\
\hline
\end{tabular}

Fuente: el autor.

Con respecto al grado de escolaridad de los concejales, se puede determinar que en su gran mayoría tienen educación superior en pregrado y, otro tanto, tiene nivel de posgrado. Este factor, el del grado de escolaridad está estrechamente relacionado con un aspecto de suma importancia para el tema de la profesionalización de la política, la educación formal le da al político cierto nivel formativo, que le debería aportar junto con su experiencia para lograr una ejecución idónea en su función, por supuesto que no estamos en presencia de un escenario de tecnopolítica (Alcántara, 2012). Parece no haber evidencias de alta especialización en temas específicos por parte de los concejales municipales.

Los concejales son profesionales en distintas áreas, que se han interesado, algunos por seguir el camino de la educación, pero no parecen pertenecer al grupo de los altamente especializados o técnicos en una materia(s) determinada(s). Un 76,5\% de los encuestados afirman tener por lo menos un grado universitario, por lo que nos encontramos ligeramente por debajo del rango del perfil del político profesional, realizado por Alcántara para América Latina, que plantea un 82,3\% con grado universitario o de posgrado. 
Figura 1. Porcentaje de representación durante la actividad como concejales municipales

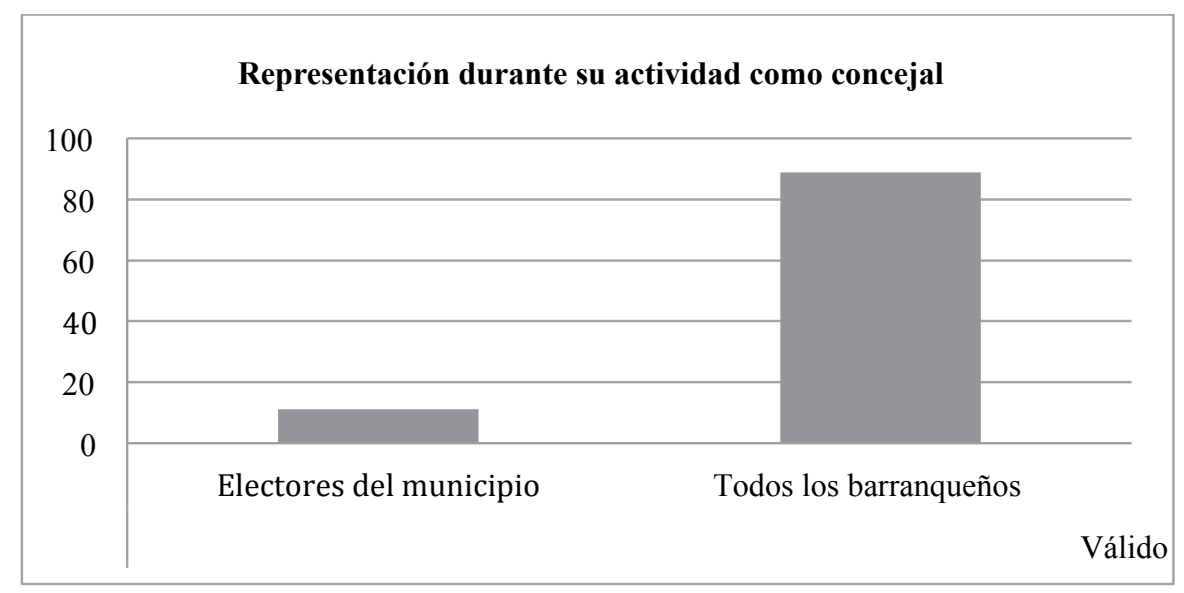

Fuente: el autor.

Respecto a las razones que se piensa han influido en la elección como concejales municipales, es claro que la razón con más peso es la concerniente a la campaña electoral. Al parecer denotaría que los concejales atribuyen su elección a su talento como líderes políticos, y a la combinación de dotes innatas, mixtas y adquiridas para consolidar su proyecto político en la ciudad. Ahora bien, el $80 \%$ de los concejales encuestados manifiesta representar los intereses de todos los barranqueños, lo cual evidencia el convencimiento que se trabaja desde la corporación, para una comunidad en general y no para un grupo en particular, llámese partido o movimiento político. Este dato se hace más importante, cuando se cruza con la gestión real de los concejales, en cuanto a los proyectos promovidos, los temas sobre los cuales versan estos proyectos y más allá de la gestión, el seguimiento de los mismos en cuanto a su puesta en marcha o ejecución, es decir, el impacto que se genera a los barranqueños en general. 
Figura 2. Principales problemas de la ciudad desde la perspectiva de los concejales

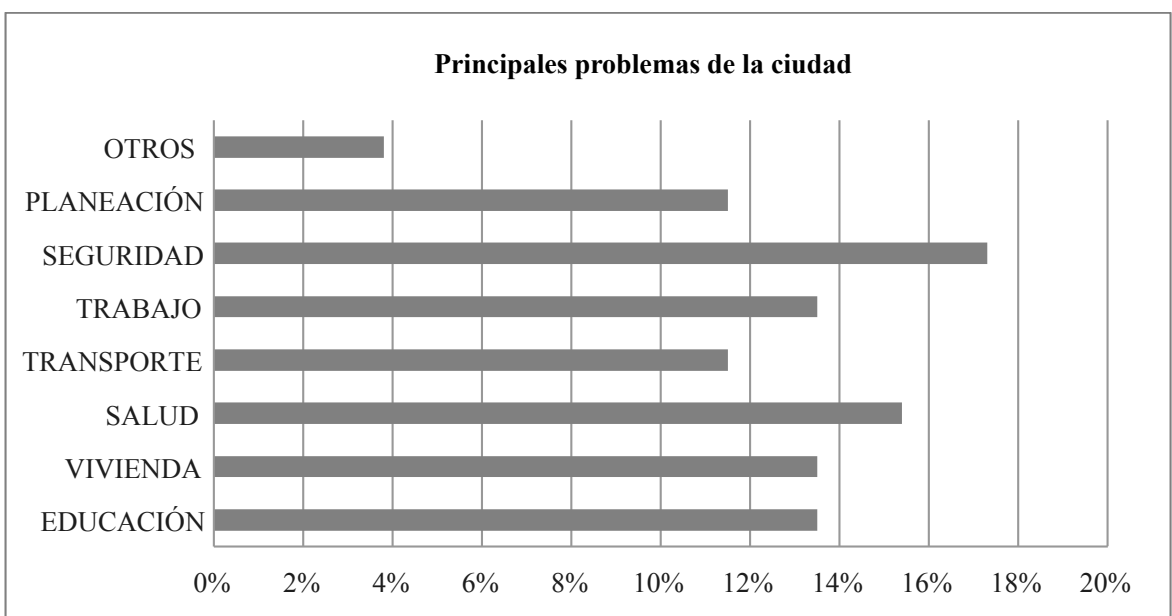

Fuente: el autor.

Los principales problemas que detectan en la ciudad los concejales, se encuentran en materia de seguridad, salud, transporte y educación, sin duda esta posición asumida por los concejales guarda relación de coherencia con la problemática real que vive la ciudad de Barrancabermeja desde hace décadas. Además de ser estos problemas coherentes, con toda una problemática que se vive en muchos casos a nivel departamental y nacional. Estos cuatro temas en la gran mayoría del territorio colombiano están aún sin resolver, y en Barrancabermeja, por supuesto, son temas que se encuentran en la agenda y están pendientes de resolución de forma estructural e integral.

\section{Experiencia}

Tabla 5. Años en los que han sido elegidos los concejales

\begin{tabular}{lcccc}
\hline $\begin{array}{c}\text { Años elección } \\
\text { concejales }\end{array}$ & Frecuencia & Porcentaje & \%Válido & \%Acumulado \\
\hline Elegidos por primera vez & 6 & 35,2 & 35,2 & 35,2 \\
$2001-2014$ & 5 & 29,4 & 29,4 & 64,6 \\
2008,$2012 ; 2014$ & 2 & 11,8 & 11,8 & 76,5 \\
$2008-2015$ & 4 & 23,5 & 23,5 & 100,0 \\
\hline \multicolumn{1}{c}{ Total } & 17 & 100,0 & 100,0 & \\
\hline
\end{tabular}

Fuente: el autor. 
Respecto al inicio de la carrera política, la mayoría, es decir el 70\% de los encuestados, inició su carrera política dentro de un partido o movimiento político. Este es un porcentaje que termina dándole un matiz importante al análisis, la identificación y pertenencia a un partido o movimiento político, ha estado presente desde un principio en la carrera política la gran mayoría de concejales encuestados. Los problemas de representación e identificación política de los que tanto se ha hablado y escrito en los recientes treinta años, en esta cifra parece encontrar su justa medida. Y sirve para el análisis conocer como gran cantidad de los políticos, han tenido un contacto inicial con un partido o movimiento político, que ha promovido su carrera a lo largo de años en el oficio de ser político.

Igualmente, es llamativo que otros grupos sociales, como son las organizaciones estudiantiles, se han mantenido y han sobrevivido como verdaderas canteras de líderes políticos. El partido político con mayor influencia en la ciudad de Barrancabermeja es el partido liberal, al cual han pertenecido más del $40 \%$ de los encuestados. Es de resaltar lo referido por algo más del $25 \%$ de los encuestados, frente a la razón o razones que influyeron para su elección como concejales, manifiestan que la curul obedece a un esfuerzo propio, lo cual puede estar en franca contradicción con lo afirmado por algo más del $65 \%$ respecto a la pertenencia a un partido o movimiento político. La pregunta que surge de inmediato es si realmente, la estructura política está funcionando en buena forma o no, frente a la promoción sistemática de líderes, para la ciudad de Barrancabermeja.

Frente a la trayectoria política de los concejales encuestados, hay que afirmar que el $35 \%$ de los encuestados se encuentran por primera vez en la corporación, y solo uno de ellos lleva más de diez años ejerciendo el cargo como concejal. Con anterioridad al cargo como concejal municipal, solo un concejal ocupa un cargo de elección popular, es el caso de uno de los concejales que ocupó el cargo de diputado. La trayectoria de un gran porcentaje de los concejales, el $90 \%$, ha pasado por el ejercicio de profesiones como las de abogado, administrador en el sector petrolero, comerciante, funcionario público, docente universitario, empresario, entre otros.

\section{Talento sumado a la experiencia}

Tabla 6. De izquierda a derecha como se sitúan los concejales

\begin{tabular}{lcccc}
\hline Tendencia política & Frecuencia & Porcentaje & \%Válido & \%Acumulado \\
\hline Izquierda & 2 & 11,8 & 11,8 & 11,8 \\
Centro-Izquierda & 8 & 47,0 & 47,0 & 58,8 \\
Centro-Derecha & 6 & 35,3 & 35,3 & 94,1 \\
Ninguna & 1 & 5,9 & 5,9 & 100,0 \\
\hline \multicolumn{1}{c}{ Total } & 17 & 100,0 & 100,0 & \\
\hline
\end{tabular}

Fuente: el autor. 
En cuanto a la pregunta sobre la ideología media presente en los concejales municipales, existe prácticamente una tendencia compartida, que no se aleja del perfil de político profesional para América Latina propuesto por Alcántara, la mayoría se inclina por ubicarse en centro derecha con un porcentaje del $44 \%$, el restante $66 \%$ se ubica en la izquierda, centro izquierda y uno de los participantes que afirma no tener ubicación. De esta forma, nos podemos dar cuenta que prácticamente se reparten los concejales en proporciones equivalentes entre centro izquierda y centro derecha. Los concejales responden de forma coherente esta pregunta, junto con la pregunta que indaga sobre la ubicación que a su vez, cada uno le da a su partido o movimiento político.

Es preocupante que de los diecisiete concejales encuestados, solo uno de ellos haya presentado durante los años 2012, 2013 y lo que va del 2014 más de un proyecto de acuerdo, es decir, el $90 \%$ de los concejales o no ha presentado proyectos de acuerdo o a lo sumo ha presentado un proyecto. Indicaría esto que la competencia funcional no está funcionando para el caso del concejo de Barrancabermeja, y existe una muy baja producción en cuanto a la esencia verdadera de la corporación de carácter municipal. Es más preciso, afirmar que acaso el $33 \%$ de los concejales ha presentado proyectos de acuerdo, pero la aprobación de los mismos ha sido escasa, pues más del $50 \%$ de estos proyectos de acuerdos no han sido aprobados por parte de la corporación.

La principal gestión frente a la comunidad, precisamente desde el anterior análisis se puede matizar, diciendo que no parece corresponderse la ejecución en cuanto a proyectos de acuerdo con la gestión frente a la comunidad, se esperaría que la principal gestión de los concejales pasara por los temas de más relevancia a nivel municipal, pero no pasa por ahí la gestión. Y de todas formas la gestión es mínima frente a la real problemática de Barrancabermeja. La producción es muy baja en cuanto a proyecto de acuerdo, y después se incluyen otros temas que no tienen mucho que ver con los problemas que realmente tiene la ciudad. Por lo tanto, se puede afirmar que la gestión frente a la comunidad no guarda coherencia con lo que realmente necesita y requieren el municipio y sus ciudadanos. Cuando se dice ciudadanos, se hace referencia principalmente a aquellos que se encuentran en los estratos 1, 2 y 3, que es donde los concejales ubican principalmente sus electores.

Respecto a la opinión de otro(s) cuando se toman decisiones políticas, es interesante el hecho de que se afirme, por parte de los concejales, que se tiene en cuenta el grupo de sus electores, no queda claro el mecanismo por el cual se logra que el grupo de electores incida de forma progresiva y real en la toma de decisiones políticas de los distintos concejales municipales. En su orden los votantes de su partido, los medios de comunicación, la opinión pública en general, los grupos de interés y el Gobierno municipal tienen un lugar privilegiado en la toma de decisiones políticas de los concejales. Al parecer, una gran cantidad de sectores políticos y sociales tienen incidencia directa y ponderable en la toma de decisiones políticas de los concejales municipales. No parece ser muy sano para la democracia y para el desarrollo de una ciudad de las dimensiones de Barrancabermeja, que tan variados grupos o sectores de la vida pública y privada del municipio tengan incidencia en este aspecto. 
Figura 3. Características que creen dominar los concejales

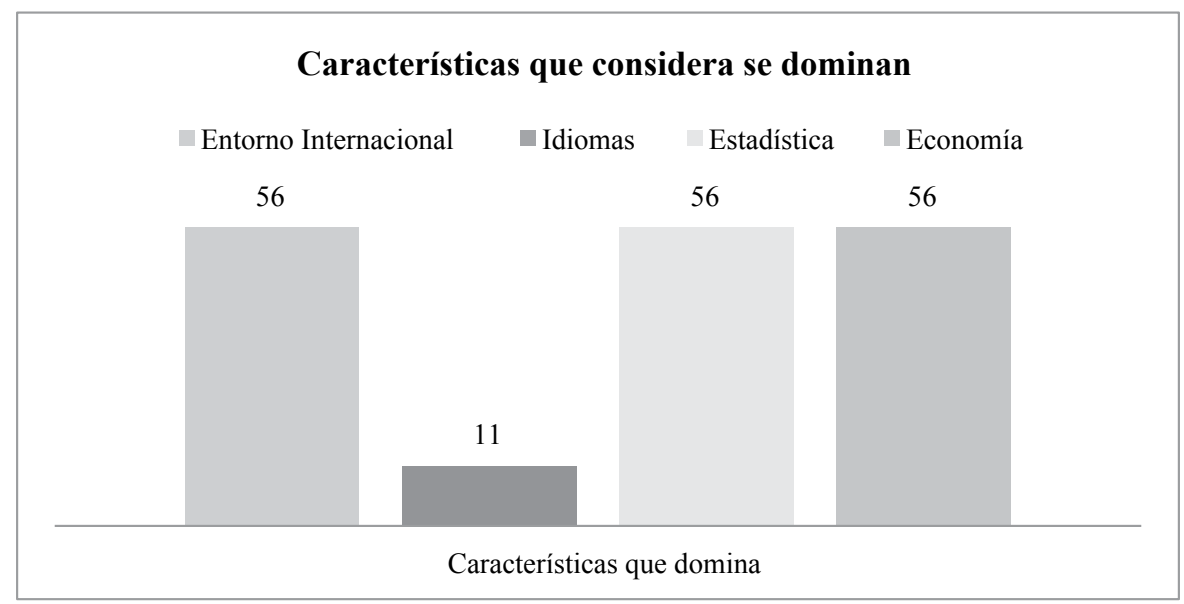

Fuente: el autor.

Finalmente, dentro de las características que dominan los concejales, se encuentra que las dos características que dominan con mayor suficiencia son oralidad y técnicas de negociación, y la que afirman no dominar es el inglés. Las demás características, entorno internacional, estadística, historia y economía se encuentran en la media de dominación entre el grupo encuestado. Por supuesto, estas características son fundamentales dentro del perfil del político profesional, sin el dominio de estas será muy complejo el proceso de profesionalización de la política. En el interior de los partidos o movimientos políticos con representación en el Concejo Municipal de Barrancabermeja no se ofrecen programas de capacitación ni formación para los líderes locales que aspiran a tener presencia en la corporación municipal, esta es una de las falencias evidenciadas en las estructuras políticas con presencia en la ciudad, y es a su vez una de las debilidades que tiene directa relación con un bajo grado de profesionalización en los políticos de Barrancabermeja.

Frente al tema de rendición de cuentas, es llamativo que el 90\% afirma rendir cuentas de su gestión como concejal municipal, lo que no está claro es la forma en cómo se realiza esta rendición de cuentas. El 40\% de los encuestados afirma que lo hace frente a su electorado, pero definitivamente no está claro el mecanismo utilizado. Se recomienda para futuras investigaciones ahondar en el funcionamiento de estos mecanismos, porque se tiene como hipótesis que realmente el electorado no llega a conocer una real rendición de cuentas de la gestión en el orden local.

En primera instancia, este trabajo desea darle al lector una representación, teniendo en cuenta las características por las que se indagó con la encuesta autodiligenciada, en el camino de conocer si estas características son o no compartidas por los concejales seleccionados en la muestra. 
Tabla 7. Cuadro comparativo de características compartidas entre concejales

\begin{tabular}{|c|c|c|}
\hline Características & Compartida & No compartida \\
\hline Género & & $\mathrm{X}$ \\
\hline Grado de escolaridad & & $\mathrm{X}$ \\
\hline Inicio de carrera política en un partido político & $\mathrm{X}$ & \\
\hline Experiencia en otros cargos de elección popular & & $\mathrm{X}$ \\
\hline Creen que representan a los barranqueños en su gestión & $\mathrm{X}$ & \\
\hline Toma de decisiones tienen en cuenta a todos sus electores & $\mathrm{X}$ & \\
\hline Se hablaba de política en su infancia & & $\mathrm{X}$ \\
\hline Familiar cercano dedicado a la política & & $\mathrm{X}$ \\
\hline Calificativo político en un continuum de izq. a der. & & $\mathrm{X}$ \\
\hline Calificativo político del partido en un continuum de izq. a der. & & $X$ \\
\hline Creyente en materia religiosa & $\mathrm{X}$ & \\
\hline Concejal a tiempo completo & & $\mathrm{X}$ \\
\hline Concejal a tiempo parcial & $\mathrm{X}$ & \\
\hline Perspectiva de los problemas de la ciudad & & $\mathrm{X}$ \\
\hline No. de proyectos de acuerdo presentados por período & & $\mathrm{X}$ \\
\hline Asuntos que se han gestionado en favor de su comunidad & & $\mathrm{X}$ \\
\hline Conocimiento de entorno internacional, economía y estadística & $\mathrm{X}$ & \\
\hline Desconocimiento del idioma inglés & $\mathrm{X}$ & \\
\hline Realiza rendición de cuentas & $\mathrm{X}$ & \\
\hline Forma como se realiza la rendición de cuentas & & $\mathrm{X}$ \\
\hline
\end{tabular}

Fuente: el autor.

\section{A MODO DE CONCLUSIÓN}

La formación académica de los concejales de Barrancabermeja es aceptable para el desempeño de las funciones propias del cargo. Es claro, que en el tema de la dedicación, no hay evidencia para hablar que exista una dedicación de tiempo completo, hay un alto porcentaje de concejales que combinan su función con otras actividades de índole profesional y personal. Frente al aspecto que la teoría nos enseña cómo trabaja duro en un líder político, no parece ser un indicador de trabajo duro, es el dato que arroja la encuesta en cuanto al tiempo de dedicación de los concejales municipales. Seguramente no puede hablarse de trabajo duro, cuando se desvela que quince de diecisiete concejales combinan simultáneamente su actividad política y su función edilicia con otras actividades de carácter personal, profesional y comercial. 
Esta primera categoría nos llevaría a pensar que a partir de los modelos propuesto por Habermas para entender la dinámica política, desde el Concejo Municipal se genera un escenario propicio para que el modelo decisionista se ponga en marcha.

De los concejales participantes no hay evidencia alguna que dé cuenta suficientemente de que tan técnicos o especializados en puntuales asuntos y temas son, lo que da una idea inicial del talento como segunda categoría analizada en la caracterización propuesta por este trabajo. Por supuesto, las ejecuciones y la capacidad de gestión se tienen que ver necesariamente afectadas con esta categoría, las dotes innatas, mixtas o adquiridas terminan siendo fundamentales para el tratamiento que dan los líderes políticos a las distintas problemáticas y se terminan convirtiendo en elementos diferenciales para hablar de un político profesional o no. Desde esta categoría, al igual que la anterior, en términos de Habermas, también se estaría reforzando un ambiente propicio para instalar el modelo decisionista, ya que no se cuenta con el suficiente talento para poner a funcionar un modelo ni tecnocrático ni pragmatista en la dinámica política local. Ya no los partidos políticos, sino los políticos en escena y participantes de esta investigación, afirman tener capacidades y habilidades propias y necesarias de cualquier político.

No se evidenció la existencia de programas de formación en los partidos políticos con representación en la corporación, sin estos programas de formación en funcionamiento, es claro que no se ofrecen herramientas a los políticos locales para conseguir desarrollar sus capacidades y habilidades, para conseguir realizar a plenitud su talento para hacer la política, y esto también afecta la ejecución y les limita en las posibilidades de obtener resultados efectivos y eficaces en su oficio, esta situación de poca o nula capacitación termina por impactar de forma negativa al político desde la perspectiva de la profesionalización. Aquí también se reitera como este puntual aspecto, refuerza el escenario propio del modelo decisionista, sobre la posibilidad del escenario tecnocrático o pragmatista desde la óptica de Habermas.

Ahora bien, en cuanto a la experiencia, se puede concluir que algunos concejales tienen experiencia en su cargo, ya que han sido elegidos en distintos períodos en la corporación, pero hay un aspecto que parece ser determinante en el análisis en cuanto a la profesionalización, no hay un historial en cuanto a cargos públicos desempeñados por los actuales concejales, tampoco se evidencia un grado de especialización concreto en los participantes, y la vida partidista no parece estar construida desde la base, sino simplemente ser una vinculación para fines esencialmente políticoelectorales. Tal vez esta sea una de las razones que explican, la imposibilidad de encontrar un escenario propicio para que el modelo pragmatista, tenga posibilidades de ser operativo y funcional en la ciudad.

Por supuesto, la experiencia tiene que ser analizada teniendo en cuenta el rasgo que tienen en común la gran mayoría de los concejales, su dedicación es de tiempo parcial y no de tiempo completo. Habla del grado de especialización y habla del estado como controlan su labor los concejales, el aspecto atinente a la rendición de cuentas, este es un aspecto que emerge bastante confuso, en relación con las respuestas de los 
concejales. Desde esta perspectiva, la política que practican los políticos participantes parece ser un puro estado subjetivo, que difícilmente es controlable, por ejemplo a través de la rendición de cuentas, que en últimas es un control de la corporación sobre sí misma (Barreda, 2011). No parece ser probable que los participantes y su experiencia estén en la capacidad de crear, modificar o implementar políticas que satisfagan las necesidades de su sociedad, y es precisamente a través de políticas, como los políticos pueden potencialmente evidenciar su talento y su experiencia al mismo tiempo.

Una vez más, analizando desde la categoría de la experiencia a los concejales de Barrancabermeja, se concluye que existe un escenario muy lejano al propicio para dar aplicación a un modelo pragmatista. Esa ausencia de un verdadero proceso de rendición de cuentas, denota un trabajo deficiente de los concejales en cuanto a sus funciones generales y específicas, además de poner en entredicho sus competencias para hacer política enfocada hacia la solución de problemas. Una de las consecuencia más directas de no hacer una lectura correcta y comprensiva de los problemas que aquejan a la comunidad, es la nula producción de políticas que deriven en soluciones ciertas para las personas, lo que no deja de ser un escenario auténtico del modelo decisionista, donde seguramente hay pocos profesionales de la política.

La experiencia que aparentemente tendrían algunos de los concejales municipales, no redunda en decisiones que beneficien a los ciudadanos barranqueños, sería interesante hacer un análisis y desagregar las iniciativas que se han convertido finalmente en acuerdo para la ciudad, y que han tenido efectivamente un impacto en la problemática real del puerto petrolero. El trabajo de los concejales no parece guardar una relación de coherencia con la experiencia y talento encontrados en las respuestas dadas, pero sí muestra coherencia con el nivel de dedicación que se evidencia en la encuesta. Ahora bien, hay información que se relaciona con la adquisición de competencias o lo que sería desde el enfoque de profesionalización propuesto por Alcántara, el talento, algo para resaltar y es la notoria ausencia de organización en cuanto a los planes de capacitación y formación de los partidos políticos con representación en el Concejo de Barrancabermeja, y es que este factor termina debilitando a los mismos y principalmente a sus líderes políticos en el nivel local, este factor provoca la imposibilidad de consolidar un verdadero proyecto político que desde las distintas instituciones favorezca y provoque un auténtico y sostenido progreso en la ciudad. De esta forma los líderes políticos devienen en gestores de asuntos específicos, más no agentes de transformación social.

\section{REFERENCIAS}

Alcántara, M. (2010). Calidad de la democracia y retos de la política en América. Madrid: Editorial Técnos.

Alcántara, M. (2012). El oficio del político. Madrid: Editorial Técnos. 
Barreda, M. (2011a). La calidad de la democracia: Un análisis comparado de América Latina. Política y Gobierno, Núm. 2, 265-295.

Barreda, M. (2011b). La calidad de la accountability en las democracias latinoamericanas. Canadian Journal of Political Science, Núm. 1, 1-20.

Cabezas, L. (s.f.). Medición de la profesionalización de las elites parlamentarias en Bolivia, Colombia, Ecuador y Perú. Base de datos del Proyecto de Elites en Latinoamérica. Instituto de Iberoamérica de la Universidad de Salamanca. http://americo.usal.es/oir/elites/. http://campus.usal.es/ acpa/sites/default/files/ seminario_cabezas_3_2.pdf el 11 de marzo de 2014.

Cortés, A. (2002). ¿Crisis de los partidos o crisis de los partidos amateurs? Revista Avances, 43. Santiago, Chile.

García, D. (1994). Estado y sociedad, la nueva relación a partir del cambio estructural. Buenos Aires. (Tesis- Grupo Editorial Norma).

Habermas, J. (1986). Ciencia y tecnología como ideología politica cientifizada y opinión política. Madrid: Técnos.

Habermas, J. (1998). Perfiles filosófico-políticos (pp. 200-221). Madrid: Taurus Ediciones.

Maas, H. S. (1958). Factores personales y grupales en la percepción social de los líderes, en Browne, C.G., y Cohn, T.S. El estudio del liderazgo. Paidós, Buenos Aires.

Maquiavelo, N. (1981). El príncipe (Cap. XV). Madrid: Alianza Editorial.

Michels, R. (1962). Los partidos políticos. Un estudio sociológico de las tendencias oligárquicas en las democracias modernas. Buenos Aires: Amorrortu.

Northouse, P. (2001). Liderazgo: Teoría y práctica (2a ed.). Sage Publications, Inc. Thousand Oaks, London, New Delhi.

Lagroye, J. (1993). Sociología politica. Buenos Aires: Fondo Cultura Económica.

Lecnher, N. (1984). Los patios interiores de la democracia. "Especificando la política”. México: Fondo de Cultura Económica.

Parsons, T. (1960). Autoridad, legitimidad y acción política”. Nueva York: The Free Press.

Rejai, M., y Phillps, K. (1997). Leaders and Leadership. An appraisal of Theory and Research (p. 1). Westport. Preager Publishers.

Romero, M. (2005). Profesionalización de la elite política administrativa en Chile, 1990 - 2004. El proceso de mantenimiento: permanencia y circulación. (Tesis para optar título de magíster en Ciencia Política de la Universidad de Chile). Recuperado el 08 de marzo de 2014 de http://www.tesis.uchile.cl/tesis/ uchile/2005/romero_mt/sources/romero_mt.pdf

Schumpeter, J. (1984). Capitalismo, socialismo y democracia. Barcelona: Editorial Folio. 
Touchard, J. (2006). Historia de las ideas políticas (6 ${ }^{\mathrm{a}}$ ed.). Madrid: Editorial Technos. Tucker, R. (1981). Politics and leadership. University of Missouri. Columbia \& London.

Weber, M. (1967). El politico y el científico. Madrid: Alianza Editorial.

Weber, M. (1967). La política como vocación. Madrid: Alianza Editorial.

Zarate, M, J. (1972). La cárcel. California. Planeta. 